\title{
Footprints of the Korean Society for Laser Medicine and Surgery
}

\author{
Hwa Jung Ryu'1, Yoon-Seok Chang², Yoon-Ki Park ${ }^{3}$, Sang-Keun Park', Phil-Sang Chung ${ }^{5}$, \\ Hwoe-Young Ahn' ${ }^{6}$, Hong Jig Kim
}

\author{
${ }^{1}$ Department of Dermatology, Korea University College of Medicine, Seoul, Korea \\ ${ }^{2}$ Department of Obstetrics and Gynecology, Maria Hospital, Seoul, Korea \\ ${ }^{3}$ Department of Dermatology, Korean Armed Forces Capital Hospital, Seoul, Korea \\ ${ }^{4}$ Department of Neurosurgery, Inje University Paik Hospital, Seoul, Korea \\ ${ }^{5}$ Department of Otorhinolaryngology-Head and Neck Surgery, Dankook University College of Medicine, Cheonan, Korea \\ ${ }^{6}$ Department of Otorhinolaryngology-Head and Neck Surgery, Hallym University College of Medicine, Seoul, Korea \\ ${ }^{7}$ Department of Dermatology, Ohkims Skin \& Laser Clinic, Seoul, Korea
}

\section{BEGINNING}

The Korean Society for Laser Medicine and Surgery (KSLMS) was inaugurated June 13, 1983 as Inaugural Meeting and Symposium was held mainly by Su-Deok Lim and Yun-Seok Chang. The 1st International Laser Symposium was also held, and it was a sign of the beginning of a new field of medical profession in the Republic of Korea. In the following year, 1984, a regular symposium and a general meeting were held in the auditorium of the Seoul National University Hospital, but no uniformed cooperation was made since many medical departments gathered. Until 1983, specific activities had not been performed.

\section{GROWTH}

As laser technology progressed rapidly in the 1990s, necessity of associations related with laser appeared. In 1993, the Society held a joint symposium and a general assembly together with the Society of Laser Treatment led by Tae-Gweon Lee at the Ramada Renaissance Hotel. In 1994, the two societies were integrated, and a spring symposium and a general assembly were held at the Samjeong Hotel. Approximately experienced 100 directors were selected to make a firm footstone for more vitalized activities of the Society. Led by Professors, Byeong-Sam Ku, Sang-Keun Park, Yun-Gi Park, Yeong-Jae Hong, Sung-Won Kwon, growth of the Society was started. On the July 7, 1995, at the conference room on the 8th floor of Korea University Anam Hospital, the entire board of directors met together. Soon, the Society was registered as a sole society in the medical laser field by the Korean Academy of Medical Sciences.
In the early period, laser was given attention mainly from Dermatology, Plastic Surgery and Gynecology. Recently, new attention was paid to laser from spinal operations in neurosurgery. From 2001, the safety of laser devices came to be emphasized. Hands-on workshops for laser device usage have been held during laser symposia of the Society or in the Medical Laser Research Center in Dankook University alternately year by year. The hands-on workshops included theoretical training on the principles and safety of lasers and practical training on $\mathrm{CO}_{2}, \mathrm{Nd}$ YAG/KTP and Holmium lasers. Great participation of nurses and technicians handling laser devices in the operating rooms as well as doctors was done. Every year, around 30 participants have received the certificate. As above, the Society tried to lay the groundwork for the introduction of a system of certification for health care providers who will use lasers, and contributed to creating public consensus to consider ethnical issues about the use of lasers.

KSLMS had published the Journal of The Korean Society of Medical Laser' on a non-periodical basis since the first issue in May 1984. However, from 1998, KSLMS had published 'the Journal of Korean Society for Laser Medicine and Surgery' once a year. In 2012, on the purpose to make KSLMS an internationally well recognized society, under the auspices of Hong-Jik Kim, the chairman of the society and Hwoe-Young Ahn, the president of the society, the journal was renamed 'Medical Laser; Engineering, Basic Research, and Clinical Application'. Led by a publishing director, SeungKuk Baek, a new editorial committee was established. Currently, international editorial board members are being recruited. In addition, the website was constructed, and the online submission system was completed. To 
be included in Science Citation Index (SCI), the Society is preparing quarterly English publication, and the first English issue will be published between late 2012 and early 2013.

The current symbol of KSLMS was designed by Professor, Sang-Keun Park. The letter K that lies sideways stands for 'Korea', and the color 'red' represents 'laser'. Thanks to continual efforts to make relationship with American Society for Laser Medicine and Surgery (ASLMS), in 1997, KSLMS received some feedback from ASLMS. On April 5, 1998, Professor Byeong-Sam Gu attended a luncheon meeting where representatives of international laser societies participated.

Use of laser devices by non-medical personnel produced serious problems. Therefore, our endeavors to make safety and administration regulations for laser use have been continued. Additionally, we struggled to prevent oriental medical treatments using low-power lasers on the vessels. We created the guidelines for the use of medical lasers in 2003, and sent official letters that explains the need for laser certification to the Ministry of Health \& Welfare, Korea Hospital Associations etc. Through these efforts, the Korea Food \& Drug Administration (KFDA) published and distributed the safety guidelines for medical lasers as our society played a leading role.

In 2002, our website was constructed at www.kslms. or.kr. It has provided information regarding news, events, articles and members.

Domestic distribution of lasers has been rapidly done since the 1990s. However, various side effects occurred as non-medical personnel were involved and many physicians were not familiar with laser usage. The tasks our society should conduct such as preparing training courses and preventing non-medical personnel from performing laser treatments have been increased. Thus, November 8, 2009, KSLMS enacted the Codes of Ethics for Medical Lasers and held a proclamation ceremony. The Codes consist of 13 articles that stipulate reasonable grounds, protection of patients' interests and other contents based on scientific principles in the application of laser-related technology to medical treatments. And in 2012, the training education for the medical laser was held for the first time.

KSLMS is an organization of medical-laser experts. Although its members came from various medical fields, KSLMS has solidly progressed since its foundation in 1983 thanks to members' effortful cooperation based on professional homogeneity.

The 29-year-old KSLMS is in a desperate effort to be reborn as an internationally-leveled society. As KSLMS collected various voices from different fields on the basis of the common theme, 'laser', it will make great contribution to medical treatments and further development of laser-related research.

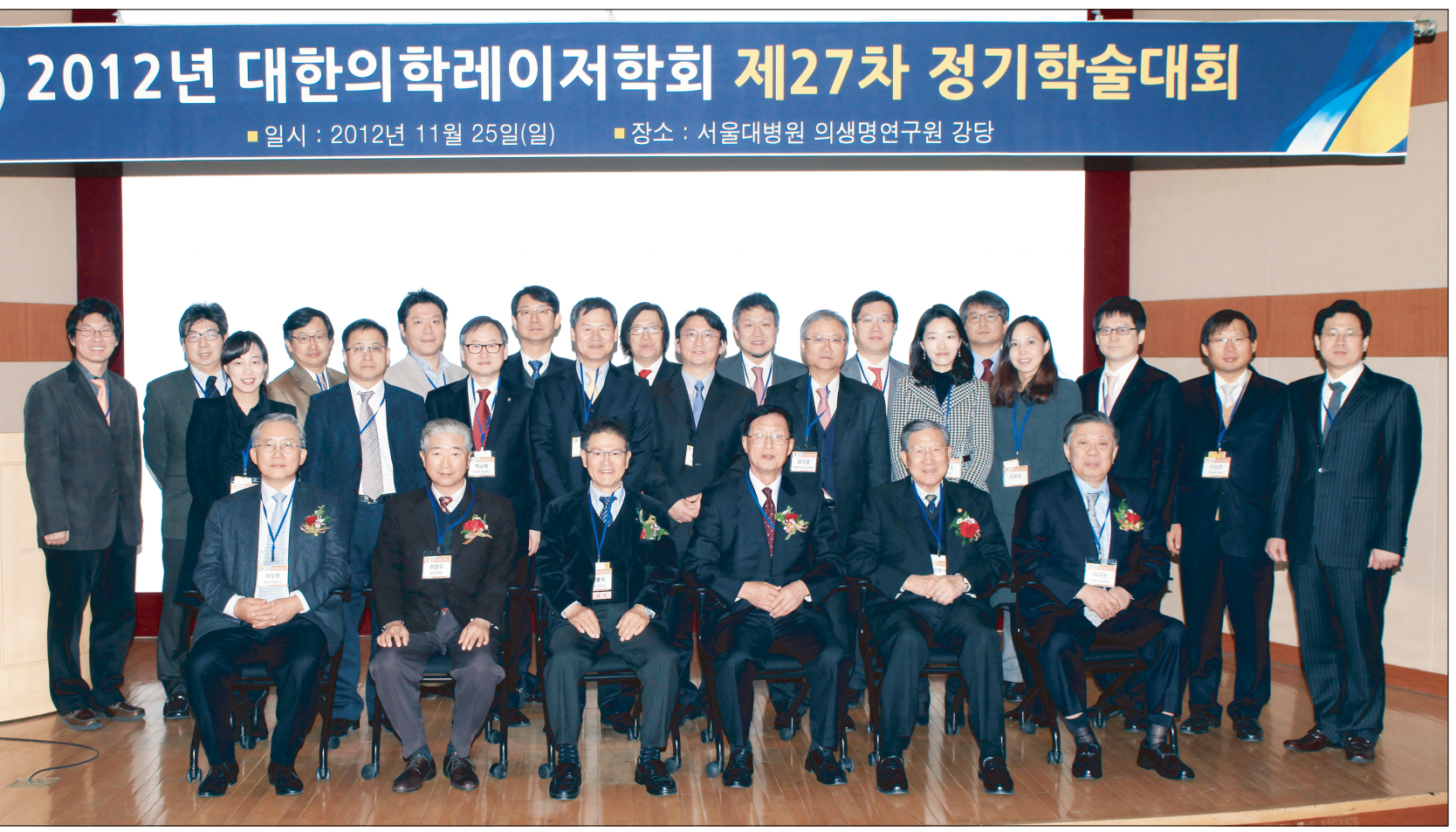

Fig. 1. KSLMS 2013 27th Annual Meeting was held in Seoul National University at November 25th, 2012. 